\title{
A novel strategy for efficient disaccharides synthesis from glucose by $\beta$-glucosidase
}

\author{
Kangle Niu', Zhengyao Liu', Yuhui Feng ${ }^{1}$, Tianlong Gao', Zhenzhen Wang ${ }^{1}$, Piaopiao Zhang ${ }^{2}$, Zhiqiang Du', \\ Daming Gao ${ }^{3}$ and Xu Fang ${ }^{1,4^{*}}$ (D)
}

\begin{abstract}
Oligosaccharides have important therapeutic applications. A useful route for oligosaccharides synthesis is reverse hydrolysis by $\beta$-glucosidase. However, the low conversion efficiency of disaccharides from monosaccharides limits its large-scale production because the equilibrium is biased in the direction of hydrolysis. Based on the analysis of the docking results, we hypothesized that the hydropathy index of key amino acid residues in the catalytic site is closely related with disaccharide synthesis and more hydrophilic residues located in the catalytic site would enhance reverse hydrolysis activity. In this study, positive variants $\operatorname{TrCel1} \mathrm{b}^{11775}, \operatorname{TrCel} 1 \mathrm{~b}^{11775 / 1744 \mathrm{~S}}$, and $\operatorname{TrCel} 1 \mathrm{~b}^{11775 / 11745 / \mathrm{N173H}}$, and one negative variant $\operatorname{TrCe} 1 \mathrm{~b}^{\mathrm{N} 240 \mathrm{I}}$ were designed according to the Hydropathy Index For Enzyme Activity (HIFEA) strategy. The reverse hydrolysis with $\operatorname{TrCel} 1 \mathrm{~b}^{11775 / 1745 / \mathrm{N} 173 \mathrm{H}}$ was accelerated and then the maximum total production $(195.8 \mathrm{mg} / \mathrm{mL} /$ mg enzyme) of the synthesized disaccharides was increased by 3.5-fold compared to that of wild type. On the contrary, $\operatorname{TrCel1} b^{\mathrm{N} 2401}$ lost reverse hydrolysis activity. The results demonstrate that the average hydropathy index of the key amino acid residues in the catalytic site of TrCel $1 \mathrm{~b}$ is an important factor for the synthesis of laminaribiose, sophorose, and cellobiose. The HIFEA strategy provides a new perspective for the rational design of $\beta$-glucosidases used for the synthesis of oligosaccharides.
\end{abstract}

Keywords: $\beta$-Glucosidase, Hydropathy index, Disaccharide synthesis, Reverse hydrolysis reaction, Site-directed mutagenesis

\section{Introduction}

Oligosaccharides are widely distributed in nature and are used in the food and medical industries (Wang et al. 2019; Wen et al. 2018; Driguez et al. 2014; Lu et al. 2015; McCranie et al. 2014; Schmaltz et al. 2011). Oligosaccharides are mainly prepared by extraction and isolation from a variety of natural plants, by chemical synthesis or biosynthesis (Wen et al. 2018; Perugino et al. 2004; Cheng et al. 2019). Extraction from plants is limited by the source plant and its terrestrial distribution. The biosynthesis of oligosaccharides via enzymatic synthesis technique in vitro has recently received increasing

\footnotetext{
*Correspondence: fangxu@sdu.edu.cn

1 State Key Laboratory of Microbial Technology, Shandong University, Qingdao 266237, China

Full list of author information is available at the end of the article
}

attention due to attributes including mild reaction temperature and excellent regio- and stereo-selectivity without the need for masking of functional groups (Moracci et al. 2001). Enzymatic synthesis of oligosaccharides is mainly catalyzed by glycosidases or glycosyltransferases (Perugino et al. 2004). Synthesis of oligosaccharides by glycosidases has many advantages that include of simplicity, reliability, ease of operation, and broad substrate specificity (Cobucci-Ponzano et al. 2011; Salgado et al. 2018), compared with catalysis by glycosyltransferases, which is the absolute conservation on the substrate (Moremen et al. 2019). These facts favor glycosidase as an economically feasible approach in the production of oligosaccharides (García et al. 2018). Furthermore, some high value-added oligosaccharides, such as laminaribiose, gentiobiose, and sophorose, have been produced using glycosidases (da Silva et al. 2017; Semenova et al. 2015). 
These oligosaccharides reportedly have potential applications in food and enzyme industries (Sanz et al. 2005; Xia et al. 2018).

In addition to glycosidic bond cleavage, glycoside hydrolases (GHs) can be used for the synthesis of glycoside bonds in vitro via reverse hydrolysis reaction without the need for cofactors, such as uridine diphosphate (Lu et al. 2015; Perugino et al. 2004; Rosengren et al. 2019; Xu et al. 2016). Recently, several glycosidases, such as $\beta$-glucosidase, $\alpha$-glucosidase, $\alpha_{-}$-rhamnosidase, $\beta$-mannosidase and $\beta$-galactosidase, have been used to synthesize glycosides via the reverse hydrolysis reaction (Lu et al. 2015; Arthornthurasuk et al. 2018; Chen et al. 2019; Ajisaka et al. 2012; Tan et al. 2016). Gentiooligosaccharides, octyl glucoside, laminaribiose, sophorose, cellobiose, and gentiobiose have been synthesized by $\beta$-glucosidase via reverse hydrolysis reaction (Semenova et al. 2015; Arthornthurasuk et al. 2018; Wang et al. 2018; Ravet et al. 1993). Furthermore, protein engineering of GHs has been widely used to eliminate hydrolytic activity and improve synthetic activity. An important strategy is to disrupt the binding of catalytic water. Honda et al. (2008) reported that hydrogen-bonding interaction with catalytic water that reduced the hydrolytic reactivity of an inverting xylanase was dramatically decreased by eliminating the retention of the nucleophilic water molecule at the key amino acid residue. Other studies have focused on improving the hydrophobicity of the entrance to the active site (Xu et al. 2016; Qin et al. 2019; Frutuoso et al. 2013) or acceptor subsite (Lundemo et al. 2013). However, the effect of hydrophobicity of amino acid residues in the catalytic site on the catalytic activity needs to be further elucidated.

In this study, we report the ability of $\beta$-glucosidase $\operatorname{TrCel1b}$ from Trichoderma reesei to simultaneously catalyze the synthesis of three disaccharides (laminaribiose, sophorose, and cellobiose) from glucose. The three-dimensional structure of $\operatorname{TrCel1b}$ was obtained and docked with cellobiose as the model of disaccharides. Based on the analysis of the docking results, we hypothesized that the hydropathy index of key amino acid residues in the catalytic site is closely related with disaccharide synthesis and more hydrophilic residues located in the catalytic site would enhance reverse hydrolysis activity.

To verify our deduction, the Hydropathy Index For Enzyme Activity (HIFEA) strategy was devised. Three hydrophobic amino acid residues in the catalytic site were mutated into hydrophilic residues, which generated the maximal change in the hydropathy index. Thus, three variants were obtained: $\operatorname{Tr} \mathrm{Cel} 1 \mathrm{~b}^{\mathrm{I}}{ }^{177 \mathrm{~S}}, \operatorname{Tr} \mathrm{Cel}-$ $1 \mathrm{~b}^{\mathrm{I177S} / 1174 \mathrm{~S}}$, and $\operatorname{Tr} \mathrm{Cel1} \mathrm{b}^{\mathrm{I1775} / 1174 \mathrm{~S} / \mathrm{W} 173 \mathrm{H}}$. Additionally, the variant $\operatorname{Tr} C e l 1 b^{\mathrm{N} 240 \mathrm{I}}$ was obtained by improving the hydrophobicity in the catalytic site. The production of synthesized disaccharides by the three variants was investigated. Total production ( $195.8 \mathrm{mg} / \mathrm{mL} / \mathrm{mg}$ enzyme) of the synthesized disaccharides was increased by 3.5 times, compared to that of the wild type. Especially, the production of laminaribiose and sophorose reached 92.3 and $71.1 \mathrm{mg} / \mathrm{mL} / \mathrm{mg}$ enzyme. The findings indicate the value of the HIFEA strategy in providing a new perspective for the rational design of $\beta$-glucosidases used for the synthesis of oligosaccharides.

\section{Materials and methods}

\section{Chemicals, plasmids, and culture media}

Laminaribiose, sophorose, $p$-nitrophenol ( $p \mathrm{NP})$, and $p$-nitrophenol- $\beta{ }_{-}$-glucoside $(p N P G)$ were purchased from Sigma-Aldrich Corporation (St. Louis, MO, USA). Kanamycin and isopropyl-1-thio- $\beta{ }_{-}{ }^{-}$-galactopyranoside (IPTG) were purchased from Gen-view Scientific Inc. (El Monte, CA, USA). The KOD-Plus-Mutagenesis Kit was purchased from Toyobo Co., Ltd. (Osaka, Japan). All other chemicals were from Sangon Biotech Co., Ltd. (Shanghai, China). Plasmid pET-32a was purchased from Invitrogen (Carlsbad, CA, USA). Restriction enzymes and T4 DNA ligase were purchased from Thermo Fisher Scientific (Shanghai, China). Primers were synthesized by Sangon Biotech Co., Ltd. Escherichia coli DH5 $\alpha$ and E. coli BL21 (DE3) were purchased from TransGen Biotech (Beijing, China).

\section{Site-directed mutagenesis}

TrCel1b (GenBank accession number: AAP57758.1) was amplified from the cDNA of T. reesei QM6a (ATCC 13631) with primers harboring EcoRI and HindIII sites, and ligated into pET-32a after it was digested with the same enzymes to obtain the recombinant vector pET32a-WT. The recombinant vectors pET-32a-I177S, pET32a-I177S/I174S, pET-32a-I177S/I174S/W173H, and pET-32a-N240I were constructed using the aforementioned KOD-Plus-Mutagenesis Kit. Oligonucleotides used in this study for plasmid constructions are listed in Additional file 1: Table S2.

\section{Expression and purification}

The constructed vectors were introduced into $E$. coli BL21(DE3) for protein expression and transformants were selected on LB plates containing $10 \mu \mathrm{g} / \mathrm{mL}$ ampicillin as previously described (Xin et al. 2016). These proteins were purified from the supernatant with His SpinTrap columns (GE Healthcare, Uppsala, Sweden) as previously described (Hou et al. 2019). The purified protein of $\operatorname{TrCel} 1 \mathrm{~b}$ and its variants was analyzed by sodium dodecyl sulfate-polyacrylamide gel electrophoresis as previously described (Schagger 2006). 


\section{Measurement of $\beta$-glucosidase activity and enzymatic synthesis of disaccharides}

$\beta$-Glucosidase activity was measured using $50 \mu \mathrm{L}$ of $5 \mathrm{mM} p$-nitrophenyl- $\beta$ - ${ }^{-}$-glucopyranoside $(p \mathrm{NPG})$ as substrate at $30{ }^{\circ} \mathrm{C}$ for $30 \mathrm{~min}$ as previously described method (Liu et al. 2016). The unit of $\beta$-glucosidase activity was defined as the amount of enzyme required to release total reducing sugar equivalent to $1 \mu \mathrm{mol} p \mathrm{NP}$ per min. The reverse hydrolysis reaction was performed in $10 \mathrm{ml}$ solution containing $3.5 \mathrm{mg} \operatorname{TrCel1b}$ or its variants, 1-8 g glucose, $500 \mu \mathrm{L}$ glycerol, and $10 \mathrm{mg}$ sodium azide in $50 \mathrm{mM}$ phosphate buffer or $0.2 \mathrm{M}$ sodium phosphate dibasic and $0.1 \mathrm{M}$ citric acid buffer and the reaction solution was kept under $30{ }^{\circ} \mathrm{C}$. The solution was sampled at specific time and three independent replicates were carried out. The sample was diluted $1 / 4-1 / 2$ with purified water before the preparation sample was analyzed by HPLC that was equipped with a refractive index detector (Hitachi, Tokyo, Japan) using an Inertsil $\mathrm{NH}_{2}$ column at $45{ }^{\circ} \mathrm{C}(250 \mathrm{~mm} \times 7.8 \mathrm{~mm}$; Shimadzu, Kyoto, Japan $)$. The mobile phase was $80 \%$ acetonitrile and a flow rate was $1.0 \mathrm{~mL} / \mathrm{min}$. The fractions containing disaccharides were collected and the laminaribiose, sophorose, and cellobiose were further identified with thin-layer chromatography (TLC) using aluminum-backed sheets of silica gel $60 \mathrm{~F}_{254}$ (0.2 mm thick; E. Merck, Germany). Elution was carried out with n-butanol:ethanol:water (5:3:2). The plates were visualized by exposure to staining solution containing $3 \mathrm{~g}$ phenol, $5 \mathrm{~mL}$ concentrated sulfuric acid and $95 \mathrm{~mL}$ alcohol followed by charring. Thermodynamic parameters for the reverse hydrolysis reaction were calculated from glucose to laminaribiose, sophorose, and cellobiose at $\mathrm{pH} 7.4$ with an ionic strength of $0.05 \mathrm{M}$ using the eQuilibrator (Noor et al. 2013).

\section{The phylogenetic and structural analysis}

The phylogenetic tree of $\operatorname{TrCel1b}$ (GenBank accession no. EGR49111.1) from T. reesei QM6a, ThBgl2 (5JBO) from $T$. harzianum, ThBgl1 (5JBK) from T. harzianum, HiBG (AII80277.1) from Humicola insolens, NkBgl (BAB91145.1) from Neotermes koshunensis and CaBglA (JX030398.1) from Caldicellulosiruptor sp. F32 was generated using MEGA. The three-dimensional struc-

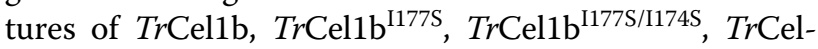
$1 \mathrm{~b}^{\mathrm{I} 177 \mathrm{~S} / \mathrm{I1} 74 \mathrm{~S} / \mathrm{W} 173 \mathrm{H}}$, and $\operatorname{TrCel1} \mathrm{b}^{\mathrm{N} 240 \mathrm{I}}$ were predicted using SWISS-MODEL (Waterhouse et al. 2018) and I-TASSEA (Yang et al. 2015) with the crystal structure of TrCel1bH13 (PDB ID: 6KHT) as the template. The structures were illustrated using PyMOL software (Delano Scientific, Palo Alto, CA). The interaction between protein and cellobiose was analyzed by LigPlot and Discovery Studio Software (Accelrys, San Diego, CA, USA).

\section{Statistics}

The Student's t-test was performed for significant differences between two groups of data. $P<0.05$ was considered statistically significant and standard deviations (SD) were calculated at least in triplicate.

\section{Results and discussion}

\section{The rational design of $\operatorname{TrCel} 1 \mathrm{~b}$}

TrCel1b (GenBank no. EGR49111.1) in T. reesei belongs to the GH1 family and shares 92, 52, 52, 39, and $38 \%$ amino acid sequence identity with GH1 family $\beta$-glucosidase ThBgl2 (5JBO), ThBgl1 (5JBK), HiBG (AII80277.1), NkBgl (BAB91145.1), and CaBglA (JX030398.1), respectively. Mature TrCel1b consists of 484 amino acids with a molecular weight of $55.1 \mathrm{kDa}$. As shown in Additional file 1: Fig. S1, $\beta$-glucosidases ThBgl1 and $T h \mathrm{Bgl} 2$, which have a relatively close evolutionary relationship with $\operatorname{TrCel1b}$, synthesize oligosaccharides (Florindo et al. 2018). The three-dimensional structure of $\operatorname{TrCel1b}$ was predicted based on the structure of its variant (PDB ID: 6KHT) by SWISS-MODEL and I-TASSER (Additional file 1: Fig. S2). The sequence of $\operatorname{TrCel1b}$ shared 100\% identity with that of 6KHT (Coverage: $98 \%$ ). A typical TIM-barrel structure of $(\alpha / \beta)_{8}$ fold was evident in $\operatorname{TrCel1b}$ (Fig. 2a), as well as the other GH1 family members, such as $\beta$-glucosidase ThBgl2.

The reverse hydrolysis reaction was performed with purified $\operatorname{TrCel1b}$ in $50 \mathrm{mM}$ phosphate buffer at $\mathrm{pH} 7.4$ under $30{ }^{\circ} \mathrm{C}$. The results of TLC and HPLC indicate that the three disaccharides-laminaribiose, sophorose, and cellobiose were simultaneously produced through the reverse hydrolysis reaction with inexpensive glucose as the glucosyl donor (Fig. 1 and Additional file 1: Fig. S3). Moreover, the production of laminaribiose and

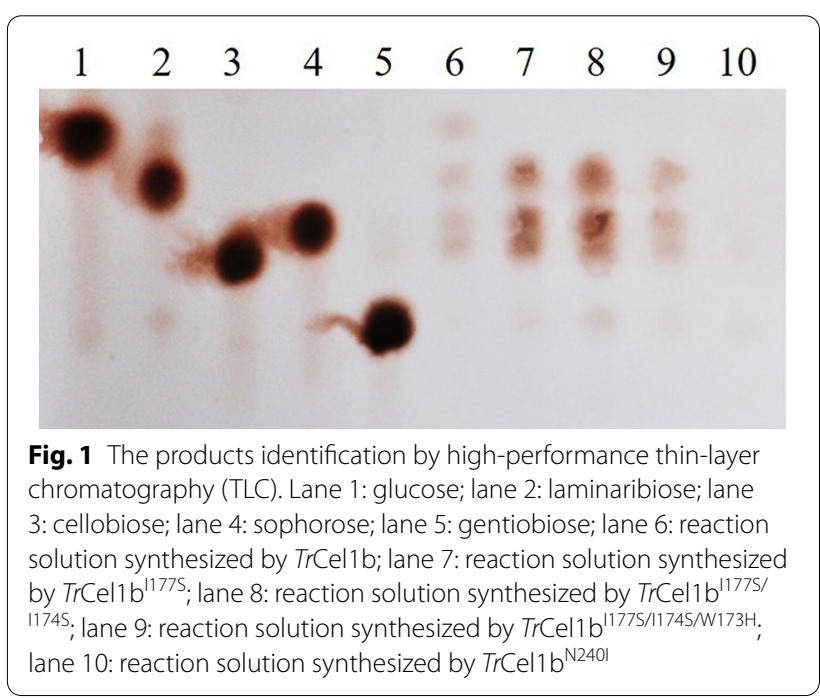



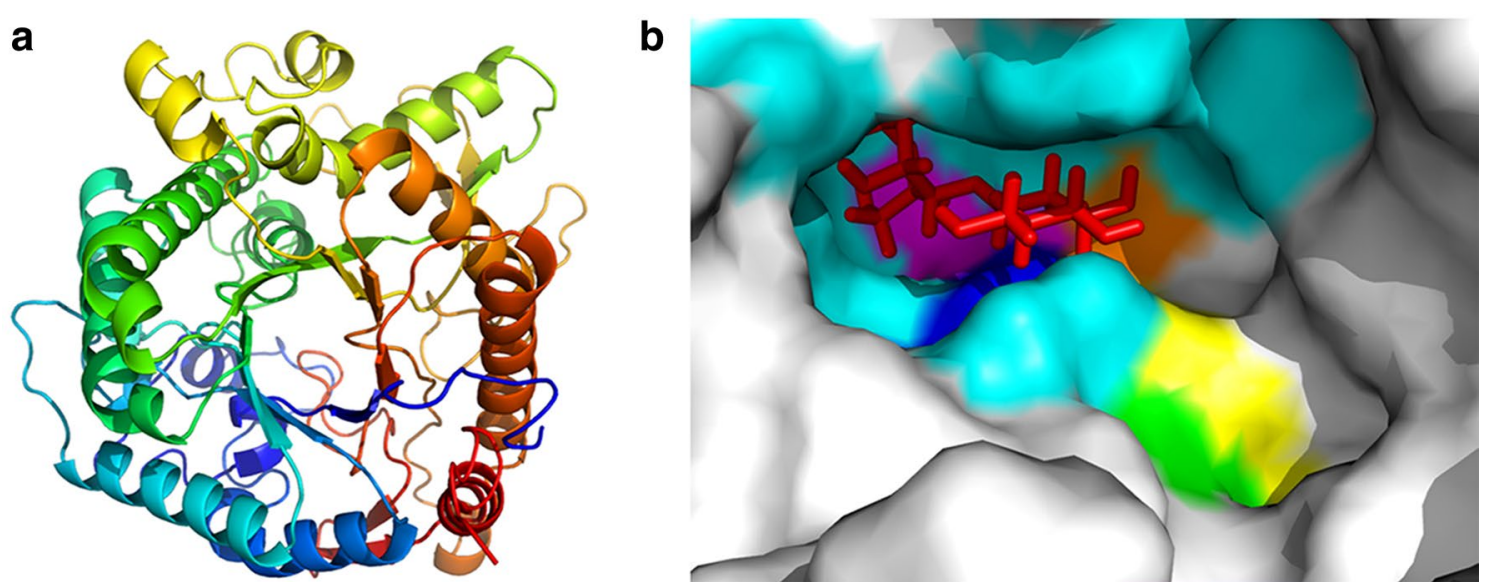

Fig. 2 Structural-guided rational design of $\beta$-glucosidase $\operatorname{TrCel} 1 \mathrm{~b}$. a Homology modeling of the 3-D structure of TrCel1 b based on the crystal structure of $6 \mathrm{KHT}$. b The flexible docking between TrCel1 b and cellobiose. Cellobiose is depicted in red, the catalytic amino acid residues - E171 and E383 are depicted in magenta, W173, 1174, 1177 and N240 are depicted in yellow, blue, green, and orange, the hydrophilic amino acid residues around cellobiose are depicted in cyan

sophorose was similar, with the production of cellobiose being markedly lower (Additional file 1: Fig. S4 A-L, A-S, A-C).

To improve the production of disaccharides, interaction between $\operatorname{TrCel1b}$ and cellobiose as the model of disaccharide was predicted with Autodock 1.5.6 (Fig. 2b). The amino acid residues surrounded by the glucose moiety in aglycone subsite $(+1$ subsite) reportedly have a significant effect on synthesis capacity compared to the residues surrounded by the glucose moiety of cellobiose at the -1 subsite (Frutuoso et al. 2013; Lundemo et al. 2013; Florindo et al. 2018; Lundemo et al. 2017). The glucose moiety of cellobiose in the aglycone subsite is surrounded by two hydrophobic residues (W173 and I174) and two hydrophilic residues (Y178 and N240), within a distance of $3.1 \AA$. The predicted distances between W173, I174, Y178, or N240 and cellobiose were 3.1, 2.8, 2.1 , and $2.1 \AA$, respectively. The extremely hydrophobic residue I177 was also found at the +2 subsite at a distance of $6.4 \AA$. The hydropathy index of I, W, Y, and N was $4.5,-0.9,-1.3$, and -3.5 , respectively.

To verify our hypothesis, the HIFEA strategy was applied to improve the reverse hydrolysis activity by reducing the average hydropathy index of key amino acid residues in catalytic site $\left(I_{\mathrm{ah}}\right)$ of $\operatorname{Tr}$ Cel1b. $I_{\mathrm{ah}}$ was defined as the sum of the hydropathy index of amino acid residues 173, 174, 177, and 240 divided by their number, namely, $I_{\mathrm{ah}}=\left(I_{\mathrm{h}, 173}+I_{\mathrm{h}, 174}+I_{\mathrm{h}, 177}+I_{\mathrm{h}, 240}\right) / 4$. Three hydrophobic amino acid residues in the catalytic site were mutated into hydrophilic residues and three variants $\operatorname{Tr} C e l 1 b^{\mathrm{I1} 77 \mathrm{~S}}, \operatorname{TrCel1} \mathrm{b}^{\mathrm{I177} / / 1174 \mathrm{~S}}$, and $\operatorname{Tr}$ Cel1 $1 \mathrm{~b}^{\mathrm{I1} 77 \mathrm{~S} /}$ I174S/W173H were obtained. Additionally, the variant $\operatorname{TrCel}-$ $1 b^{\mathrm{N} 240 \mathrm{I}}$ was obtained by improving the hydrophobicity in the catalytic site. The $\mathrm{I}_{\mathrm{ah}}$ of $\operatorname{Tr} \mathrm{Cel} 1 \mathrm{~b}$ and its variants was calculated according to the hydropathy index. The $\mathrm{I}_{\mathrm{ah}}$ of $\operatorname{TrCel1b}, \operatorname{Tr}$ Cel11b $\mathrm{b}^{\mathrm{I1775}}, \operatorname{Tr}$ Cel1 $\mathrm{b}^{\mathrm{I1775/1174S}}, \operatorname{Tr} \mathrm{Cel}-$

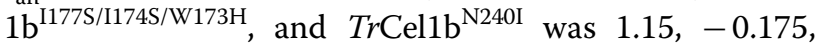
$-1.5,-2.075$, and 3.15 , respectively, which revealed that $I_{\text {ah }}$ changed along with the mutation. The hydrophobic interaction between these key amino acid residues and disaccharides was weakened when $I_{\text {ah }}$ was reduced by the mutation of the hydrophobic residues located in the catalytic site of W173, I174, and/or I177 to the hydrophilic residues, which facilitated the release of disaccharide. Finally, production of disaccharides synthesized by reverse hydrolysis was improved. On the contrary, reverse hydrolysis was repressed when $I_{\text {ah }}$ was increased by improving the hydrophobicity in the catalytic site.

\section{Identification of products synthesized by $\operatorname{TrCel} 1 \mathrm{~b}$ wild type} and its variants

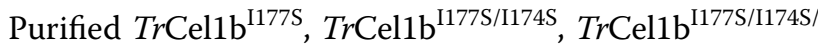
$\mathrm{W}^{173 \mathrm{H}}$, and $\operatorname{Tr} \mathrm{Cel} 1 \mathrm{~b}^{\mathrm{N} 240 \mathrm{I}}$ displayed a similar molecular weight of $74 \mathrm{kDa}$, compared to the size of $\operatorname{TrCel1b}$ (Additional file 1: Fig. S5), consistent with the molecular weight predicted by the ExPASy website (https://web.expasy.org/ compute_pi/). The products synthesized by these variants, except $\operatorname{Tr}$ Cel1 ${ }^{\mathrm{N} 240 \mathrm{I}}$, were laminaribiose, sophorose, and cellobiose, respectively (Fig. 1, lanes 7-9). The hydrolysis activities of the variants decreased as the $I_{\mathrm{ah}}$ of variants decreased (Fig. 3a) and $\beta$-glucosidase activity of $\operatorname{Tr} \mathrm{Cel1} \mathrm{b}^{\mathrm{I1} 77 \mathrm{~S} / 1174 \mathrm{~S} / \mathrm{W} 173 \mathrm{H}}$ was almost lost, compared to 0.35 $\mathrm{U} / \mathrm{mg}$ soluble protein of $\operatorname{TrCel1b}$. However, there was no significant change of $\beta$-glucosidase activity between

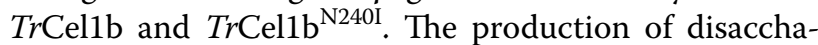
rides was enhanced as the $I_{\text {ah }}$ of the variants decreased 

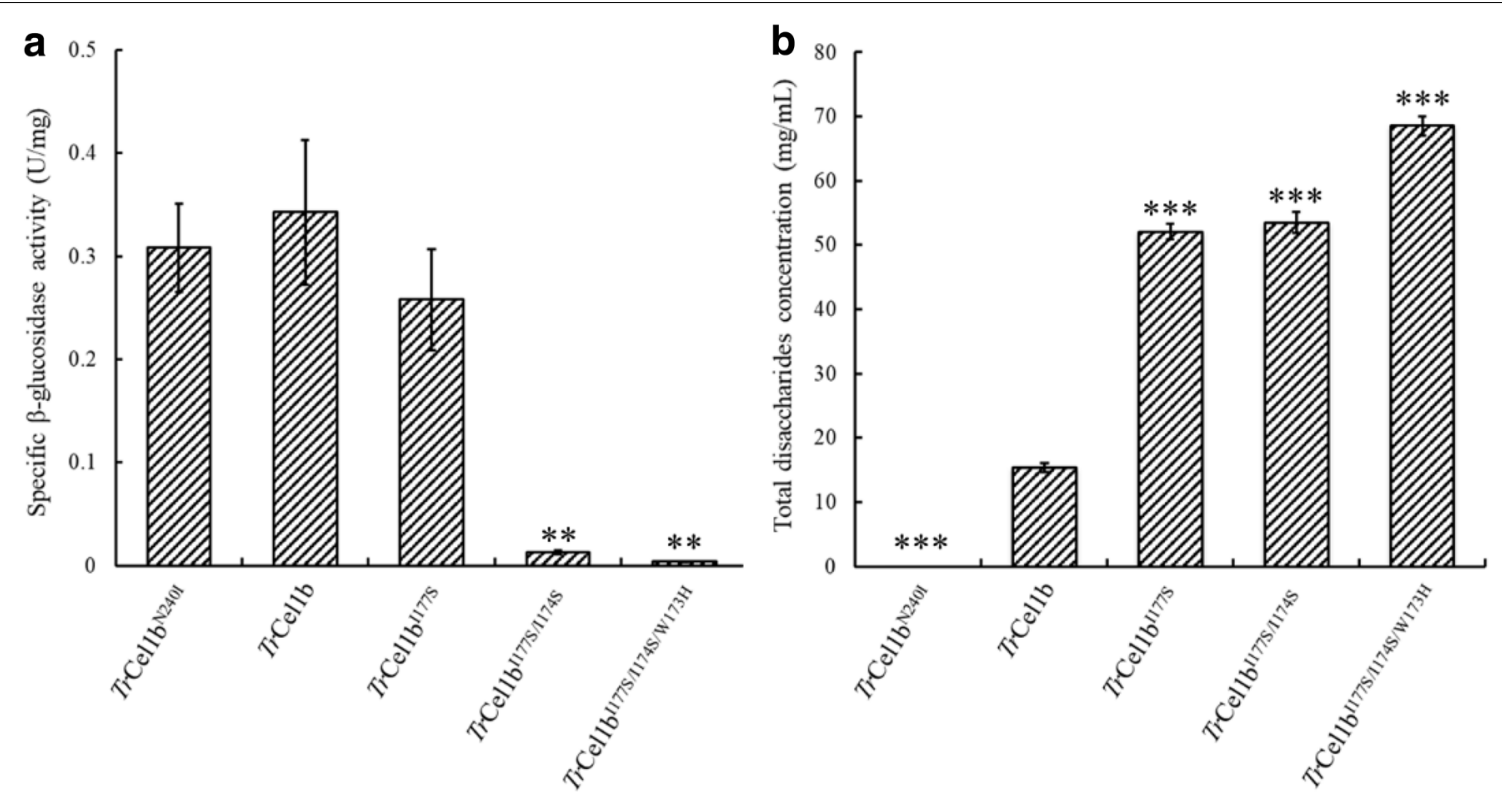

Fig. 3 The specific $\beta$-glucosidase activity (a) of TrCel1 b and its variants and the total disaccharides production (b) synthesized by $\operatorname{Tr} C e l 1 \mathrm{~b}$ and its variants using $80 \%(\mathrm{w} / \mathrm{v})$ glucose as the substrate for $72 \mathrm{~h}$ at $30^{\circ} \mathrm{C}$. Total disaccharides concentration represents the sum of the production of laminaribiose, sophorose and cellobiose synthesized by $\operatorname{TrCel} 1 \mathrm{~b}$ and its variants. ${ }^{*} p<0.05 ;{ }^{* *} p<0.01 ;{ }^{* * *} p<0.001$. The statistically significant difference was performed between $\operatorname{TrCel} 1 \mathrm{~b}$ and its variants

(Fig. 3b). The disaccharide production of $\operatorname{TrCel1b} \mathrm{b}^{\mathrm{I1} 77 \mathrm{~S} /}$ I174S/W173H increased by 3.5 times, reaching $68.5 \mathrm{mg} / \mathrm{mL}$, compared with that of $\operatorname{TrCel1b}$. On the contrary, the variant $\operatorname{TrCel1} \mathrm{b}^{\mathrm{N} 240 \mathrm{I}}$ with an $I_{\mathrm{ah}}$ of 3.15 displayed no disaccharide synthetic activity. As shown in Additional file 1: Fig. S4, the disaccharides laminaribiose, sophorose, and cello-

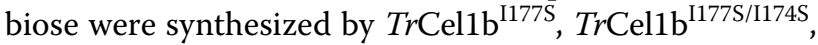

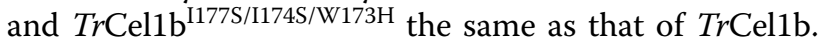
Moreover, the production of laminaribiose, sophorose,

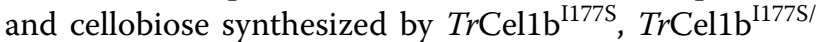

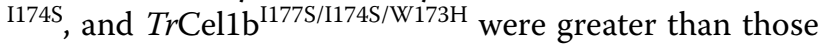
of $\operatorname{TrCel1b}$ (Additional file 1: Fig. S4). These results indicated that the decreased $I_{\mathrm{ah}}$ of $\operatorname{TrCel1b}$ was favored for the reverse hydrolysis reaction.

Glucose was used as the substrate $(10,20,40,60$, and $80 \%$ ) for reverse hydrolysis and the laminaribiose, sophorose and cellobiose production was measured by high-performance liquid chromatography (HPLC) (Additional file 1: Fig. S4). The production of laminaribiose, sophorose, and cellobiose was greatly improved as glucose concentration increased from $10 \%$ to $80 \%$. Moreover, we investigated the effects of $\mathrm{pH}$ value on synthesis activity in $0.2 \mathrm{M}$ sodium phosphate dibasic and $0.1 \mathrm{M}$ citric acid buffer (Additional file 1: Fig. S6), and then it was

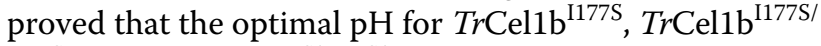
I174S, and $\operatorname{TrCel1} \mathrm{b}^{\mathrm{I1} 77 \mathrm{~S} / \mathrm{I1} 74 \mathrm{~S} / \mathrm{W} 173 \mathrm{H}}$ were 7, 6, and 6, respectively. The activity of $\operatorname{TrCel1} b^{\mathrm{I177S/1174S}}$ and $\operatorname{TrCel1b^{\mathrm {I1}77\mathrm {S}/}}$ $\mathrm{I} 174 \mathrm{~S} / \mathrm{W} 173 \mathrm{H}$ increases by $55 \%$ and $46 \%$ in comparison with $\operatorname{TrCel1b}$ at pH 6 (Additional file 1: Fig. S6). When the hydrophobic residue isoleucine at the +1 subsite of $\operatorname{TrCel1b}$ is mutated to hydrophilic residue serine, the reverse hydrolysis activity of $\operatorname{TrCel} 1 \mathrm{~b}$ is improved; when W173 at +1 subsite of TrCel1b is mutated to histidine, protonation of histidine may occur under the weakly acidic environment, which is unfavorable to reverse hydrolysis activity (Lundemo et al. 2017; Seidle et al. 2005). Thus, the total disaccharides production synthe-

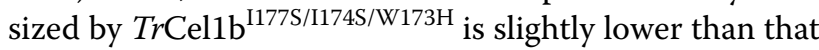
of $\operatorname{TrCel1b^{\mathrm {I1}}\mathrm {T7S}/\mathrm {I}174\mathrm {S}}$ at pH 6 (Additional file 1: Fig. S6).

The production of laminaribiose and sophorose was increased when the $I_{\text {ah }}$ value of the variants was decreased. Laminaribiose production was the highest among the three disaccharides. The maximal lami-

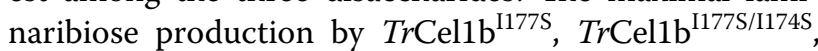

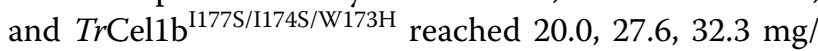
$\mathrm{mL}$, and increased 1.8, 2.8, and 3.5-fold, compared to that of $\operatorname{TrCel1b}$, respectively (Additional file 1: Fig. S4). Sophorose production was markedly higher than that of cellobiose, and its maximal production of $\operatorname{TrCel1} \mathrm{b}^{\mathrm{I1} 77 \mathrm{~S}}$,

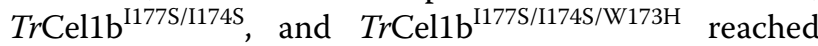
$17.8,19.9$, and $24.9 \mathrm{mg} / \mathrm{mL}$, respectively (Additional file 1: Fig. S4). These results revealed a direct relationship between the reverse hydrolysis activity and the $I_{\text {ah }}$ value of $\operatorname{TrCel1b.}$

As shown in Fig. 3b, the increased disaccharides pro-

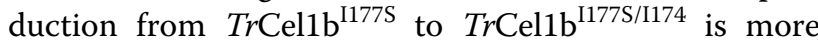


than two times higher than that from $\operatorname{Tr} C e l 1 b^{[177 S / 1174 S ~}$ to $\operatorname{TrCel1} \mathrm{b}^{\mathrm{I1775} / 1174 / \mathrm{W} 173 \mathrm{H}}$. As shown in Fig. $2 \mathrm{~b}, \mathrm{I} 177$ is located in +2 site and then W173 and I174 are located in +1 site. Our results were consistent with previous report that the position of amino acid residue as well as $I_{\text {ah }}$ value has an important influence on the disaccharides synthesis (Rosengren et al. 2014). We speculated that II77 has a more significant influence on the entrance of glucose and the release of disaccharides, compared to W173 and I174 owe to +2 site is closer to the entrance of enzyme, compared to +1 site.

To study the effect of mutation on the interaction between protein and disaccharide, cellobiose was docked with $\operatorname{TrCel} 1 \mathrm{~b}$ and its variants using Autodock software and the result of docking was analyzed by LigPlot. The hydrophobic interaction between cellobiose and the amino acid residues of $\operatorname{TrCel1} \mathrm{b}^{\mathrm{I1775} / 1174 \mathrm{~S} / \mathrm{W} 173 \mathrm{H}}$ (Fig. 4b) became weak, compared to that of $\operatorname{TrCel1b}$ (Fig. 4a). The number of residues that hydrophobically interacted with

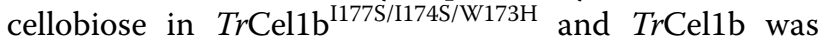
16 and 20, respectively. The hydrophobic interactions between the W173 and I174 residues and cellobiose disappeared since the two residues were mutated into the hydrophilic residues (Fig. 4a, b). These results were verified using Discovery studio (Additional file 1: Fig. S7).

\section{The relationship between the $I_{\text {ah }}$ value of $\operatorname{TrCel} 1 \mathrm{~b}$} and reverse hydrolysis activity

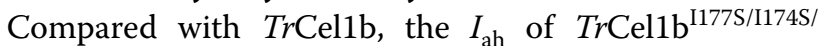
W173H decreased, which was beneficial for the release of the cellobiose product. On the contrary, the $I_{\text {ah }}$ of

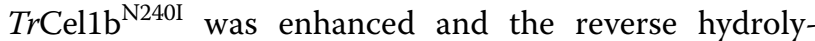
sis activity of $\operatorname{TrCel1} \mathrm{b}^{\mathrm{N} 240 \mathrm{I}}$ was completely lost (Fig. 3b) owing to the mutation of the hydrophilic residue N240 to the hydrophobic residue isoleucine (Fig. 4c). The findings provided an obvious indication of a direct relationship

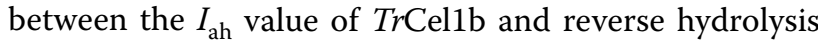
activity. When the $I_{\text {ah }}$ value of $\operatorname{Tr}$ Cell b became negative, the reverse hydrolysis activity was enhanced. On the contrary, when the $I_{\mathrm{ah}}$ value of $\operatorname{Tr}$ Cel1 $1 \mathrm{~b}$ increased, the reverse hydrolysis activity was abolished. The findings are consistent with our hypothesis that the hydropathy index of key amino acid residues in the catalytic site is closely related with disaccharide synthesis.

\section{Comparison of disaccharides production synthesized by $\beta$-glucosidases}

In this study, $\alpha$-glucosidase $\operatorname{Tr}$ Cel $1 \mathrm{~b}$ from $T$, reese $i$ was shown to simultaneously synthesize laminaribiose, sophorose, and cellobiose using a high concentration glucose as substrate. As shown in Table 1, the $\Delta_{\mathrm{r}} G^{\prime}$ of laminaribiose, sophorose, or cellobiose synthesis is $<0$ indicating it is realizable that laminaribiose, sophorose, and cellobiose were produced from glucose by $\operatorname{TrCel1b}$. Ravet et al. (1993) reported that the disaccharides were produced by $\beta$-glucosidase derived from almonds. However, most of these disaccharides were gentiobiose, rather than laminaribiose and sophorose. This was the reason why the equilibrium constant $\left(K_{\text {eq }}\right)$ of the reaction to synthesize laminaribiose, sophorose, and cellobiose (Table 1 ) was markedly lower than that of gentiobiose $\left(53.8 \times 10^{-3}\right)$. There are few reports on

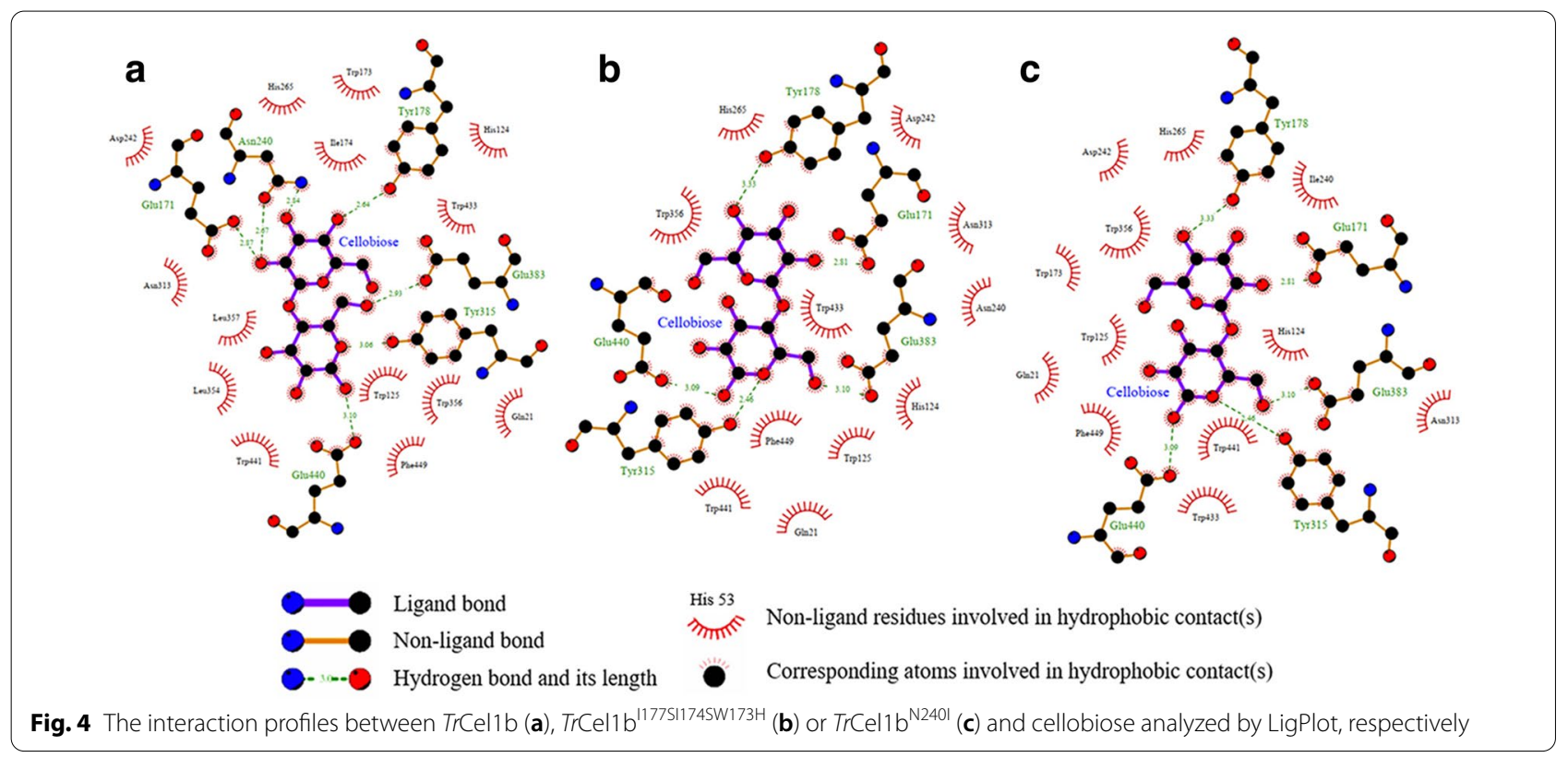


Table 1 Thermodynamic parameters for the reverse hydrolysis from glucose to laminaribiose, cellobiose, and sophorose

\begin{tabular}{llll}
\hline Process & $\boldsymbol{K}_{\text {eq }}\left(\times \mathbf{1 0}^{-\mathbf{3}}\right)$ & $\boldsymbol{\Delta}_{\mathbf{r}} \boldsymbol{G}^{\mathbf{0}}(\mathbf{k J} / \mathbf{m o l})$ & $\boldsymbol{\Delta}_{\mathbf{r}} \boldsymbol{G}^{\prime}(\mathbf{k J} / \mathbf{m o l})$ \\
\hline $\begin{array}{l}\text { 2 Glucose = laminaribi- } \\
\text { ose }+\mathrm{H}_{2} \mathrm{O}\end{array}$ & 3.5 & $14.0 \pm 6.0$ & $-44.7 \pm 6.0$ \\
$\begin{array}{l}2 \mathrm{Glucose}=\text { cellobi- } \\
\begin{array}{l}\text { ose }+\mathrm{H}_{2} \mathrm{O} \\
2 \mathrm{Glu}-\end{array}\end{array}$ & 5.4 & $12.9 \pm 3.7$ & $-45.8 \pm 3.7$ \\
cose $=$ sophorose $+\mathrm{H}_{2} \mathrm{O}$ & 3.4 & $14.1 \pm 5.0$ & $-44.6 \pm 5.0$ \\
\hline
\end{tabular}

$\Delta_{\mathrm{r}} G^{\prime 0}$ : the change in Gibbs free energy of the chemical reaction in standard $1 \mathrm{M}$ concentrations of substrates and products at $\mathrm{pH} 7.4$ with ionic strength of $0.05 \mathrm{M}$

$K_{\text {eq }}$ : the equilibrium constant of the chemical reaction in standard $1 \mathrm{M}$ concentrations of substrates and products at $\mathrm{pH} 7.4$ with ionic strength of $0.05 \mathrm{M}$

$\Delta_{\mathrm{r}} G^{\prime}$ : the change in Gibbs free energy of the chemical reaction in $4.4 \mathrm{M}$ concentrations of substrate at $\mathrm{pH} 7.4$ with ionic strength of $0.05 \mathrm{M}$

laminaribiose and sophorose synthesis, reflecting their low production. To improve the production of disaccharides synthesized by $\operatorname{Tr} C \mathrm{l} 1 \mathrm{~b}$, protein engineering was performed using the HIFEA strategy. The production of laminaribiose, sophorose, and cellobiose synthe-

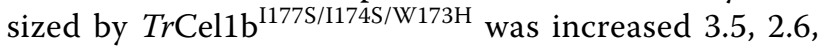
and 3.9-fold, respectively, compared to that of $\operatorname{TrCel1b}$ (Additional file 1: Fig. S4). Compared with reported $\beta$-glucosidases from different species (Additional file 1: Table S1), the maximal production of laminaribiose and sophorose by $\operatorname{TrCel1} 1 \mathrm{~b}^{\mathrm{I1} 77 \mathrm{~S} / \mathrm{I} 174 \mathrm{~S} / \mathrm{W} 173 \mathrm{H}}$ reached 92.3 and $71.1 \mathrm{mg} / \mathrm{mL} / \mathrm{mg}$ enzyme, respectively, and were higher than the results produced by $\beta$-glucosidases from Aspergillus niger, Corynascus sp., Penicillium verruculosum, T. reesei (Semenova et al. 2015), and almond (Ravet et al. 1993). To our knowledge, this is the highest production of laminaribiose and sophorose simultaneously synthesized by $\beta$-glucosidase.

\section{Conclusions}

Our results reveal that $\beta$-glucosidase $\operatorname{TrCel} 1 \mathrm{~b}$ from $T$. reesei simultaneously synthesized laminaribiose, sophorose, and cellobiose. Three variants $\left(\operatorname{TrCel1b} \mathrm{b}^{\mathrm{I177S}}\right.$,

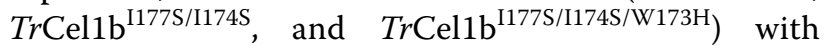
improved disaccharide production were obtained using the HIFEA strategy. The $I_{\mathrm{ah}}$ of $\beta$-glucosidase $\operatorname{TrCel} 1 \mathrm{~b}$ is an important factor for the production of laminaribiose, sophorose, and cellobiose. The decreased $I_{\text {ah }}$ value of $\operatorname{TrCel1b}$ improved the synthetic activity and reduced the hydrolytic activity. The HIFEA strategy is implicated as an avenue for the production of high valueadded disaccharides.

\section{Abbreviations}

HIFEA: Hydropathy Index For Enzyme Activity; $I_{a h}$ :The average hydropathy index of key amino acid residues in catalytic site; TLC: Thin-layer chromatography; GHs: Glycoside hydrolases.

\section{Supplementary information}

Supplementary information accompanies this paper at https://doi.org/10. 1186/s40643-020-00334-6.

Additional file 1: Fig. S1. The phylogenetic tree of $\operatorname{TrCel1b}$ and other GH1 family $\beta$-glucosidases. Fig. S2. The 3-D model of $\operatorname{TrCel} 1 \mathrm{~b}$ predicted by SWISS-MODEL (A) and I-TASSER (B) using $\beta$-glucosidase 6KHT as template. Fig. S3. Analysis of the disaccharides with HPLC. Fig. S4. The disaccharides synthesis of $\beta$-glucosidase and its variants under different concentrations of glucose. Fig. S5. SDS-PAGE analysis of purification of TrCel1b and its variants. Fig. S6. Effects of $\mathrm{pH}$ value on disaccharides synthesis. Fig. S7. The interaction profiles between $\operatorname{TrCel1b}(\mathbf{A}), \operatorname{TrCel1} \mathrm{b}^{1177511745 W 173 \mathrm{H}}(\mathbf{B})$ or $\operatorname{TrCel} 1 \mathrm{~b}^{\mathrm{N} 240 \mathrm{I}}(\mathbf{C})$ and cellobiose analyzed by Discovery Studio 4.5 , respectively. Table S1. The comparison of the production of laminaribiose and sophorose synthesized by $\beta$-glucosidase from different species. Table S2. Primers used in this study.

\section{Acknowledgements}

We thank Ms. Zhifeng Li, Ms. Rui Wang, and Mr. Chengjia Zhang from State Key Laboratory of Microbial Technology for assistance in protein separation and purification. Thanks to Prof. Huifeng Jiang from Tianjin Institute of Industrial Biotechnology, Chinese Academy of Sciences for his contribution during Discovery Studio analyses. Thanks to Prof. Luying Xun for revising the manuscript.

\section{Authors' contributions}

$\mathrm{KN}, \mathrm{ZL}, \mathrm{YF}$ and TG carried out protein mutagenesis and purification. KN, ZW, PZ, DG carried out biochemical assays. KN, ZL and XF carried out structural modeling and docking. ZW and XF conceived of the study. ZD and XF oversaw experimental and computational work. KN, ZD and XF designed experiments and wrote the manuscript. XF coordinated the project. All authors read and approved the final manuscript.

\section{Funding}

This work was supported by National Key R\&D Program of China (No. 2018YFA0901700), Key Technologies R\&D Program of Shandong Province (No. 2018GSF121021), the 111 Project (No. B16030), the State Key Laboratory of Microbial Technology Open Projects Fund and National Natural Science Foundation of China (No. 31870785 and 31570040).

Availability of data and materials

All data supporting this article's conclusion are available.

Ethics approval and consent to participate

Not applicable.

\section{Consent for publication}

Not applicable.

\section{Competing interests}

Part of the study was authorized by the patent ZL 201410438150.0.

\section{Author details}

${ }^{1}$ State Key Laboratory of Microbial Technology, Shandong University, Qingdao 266237, China. ${ }^{2}$ Yantai Huakangrongzan Biotechnology Co., Ltd, Yantai 264006, China. ${ }^{3}$ Department of Rehabilitation Science, Graduate School of Health Science, Kobe University, Kobe 6540142, Japan. ${ }^{4}$ National Glycoengineering Research Center, Shandong University, Qingdao 266237, China.

Received: 21 April 2020 Accepted: 28 July 2020

Published: 4 August 2020 


\section{References}

Ajisaka K, Yagura M, Miyazaki T (2012) A novel two-step synthesis of a-linked mannobioses based on an acid-assisted reverse hydrolysis reaction. Carbohydr Res 347:147-150. https://doi.org/10.1016/j.carres.2011.10.037

Arthornthurasuk S, Jenkhetkan W, Suwan E, Chokchaichamnankit D, Srisomsap C, Wattana-Amorn P, Svasti JT, Kongsaeree P (2018) Molecular characterization and potential synthetic applications of $\mathrm{GH} 1 \beta$-Glucosidase from higher termite Microcerotermes annandalei. Appl Biochem Biotechnol 186:877-894. https://doi.org/10.1007/s12010-018-2781-8

Chen H, Yang S, Xu A, Jiang R, Tang Z, Wu J, Zhu L, Liu S, Chen X, Lu Y (2019) Insight into the glycosylation and hydrolysis kinetics of alpha-glucosidase in the synthesis of glycosides. Appl Microbiol Biotechnol 103:9423-9432. https://doi.org/10.1007/s00253-019-10205-6

Cheng CW, Wu CY, Hsu WL, Wong CH (2019) Programmable one-pot synthesis of oligosaccharides. Biochemistry. https://doi.org/10.1021/acs.biochem. 9b00613

Cobucci-Ponzano B, Strazzulli A, Rossi M, Moracci M (2011) Glycosynthases in biocatalysis. Adv Synth Catal 353:2284-2300. https://doi.org/10.1002/ adsc.201100461

da Silva ASA, Molina JF, Teixeira RSS, Gelves LGV, Bon EP, Ferreira-Leitão VS (2017) Synthesis of disaccharides using $\beta$-glucosidases from Aspergillus niger, A. awamori and Prunus dulcis. Biotechnol Lett 39:1717-1723. https://doi.org/10.1007/s10529-017-2409-z

Driguez PA, Potier P, Trouilleux P (2014) Synthetic oligosaccharides as active pharmaceutical ingredients: lessons learned from the full synthesis of one heparin derivative on a large scale. Nat Prod Rep 31:980-989. https://doi. org/10.1039/C4NP00012A

Florindo RN, Souza VP, Mutti HS, Camilo C, Manzine LR, Marana SR, Polikarpov I, Nascimento AS (2018) Structural insights into $\beta$-glucosidase transglycosylation based on biochemical, structural and computational analysis of two GH1 enzymes from Trichoderma harzianum. New Biotechnol 40:218-227. https://doi.org/10.1016/j.nbt.2017.08.012

Frutuoso MA, Marana SR (2013) A single amino acid residue determines the ratio of hydrolysis to transglycosylation catalyzed by $\beta$-glucosidases. Protein Pept Lett 20:102-106. https://doi.org/10.2174/092986613804096757

García C, Hoyos P, Hernáiz MJ (2018) Enzymatic synthesis of carbohydrates and glycoconjugates using lipases and glycosidases in green solvents. Biocatal Biotransform 36:131-140. https://doi.org/10.1080/10242422. 2017.1349760

Honda Y, Fushinobu S, Hidaka M, Wakagi T, Shoun H, Taniguchi H, Kitaoka M (2008) Alternative strategy for converting an inverting glycoside hydrolase into a glycosynthase. Glycobiology 18:325-330. https://doi.org/10. 1093/glycob/cwn011

Hou N, Yan Z, Fan K, Li H, Zhao R, Xia Y, Xun L, Liu H (2019) OxyR senses sulfane sulfur and activates the genes for its removal in Escherichia coli. Redox Biol. 26:101293. https://doi.org/10.1016/j.redox.2019.101293

Liu K, Dong Y, Wang F, Jiang B, Wang M, Fang X (2016) Regulation of cellulase expression, sporulation, and morphogenesis by velvet family proteins in Trichoderma reesei. Appl Microbiol Biotechnol 100:769-779. https://doi. org/10.1007/s00253-015-7059-2

Lu L, Liu Q, Jin L, Yin Z, Xu L, Xiao M (2015) Enzymatic synthesis of rhamnose containing chemicals by reverse hydrolysis. PLoS ONE 10:e0140531. https://doi.org/10.1371/journal.pone.0140531

Lundemo P, Adlercreutz P, Karlsson EN (2013) Improved transferase/hydrolase ratio through rational design of a family $1 \beta$-glucosidase from Thermotoga neapolitana. Appl Environ Microbiol 79:3400-3405. https://doi.org/ 10.1128/aem.00359-13

Lundemo P, Karlsson EN, Adlercreutz P (2017) Eliminating hydrolytic activity without affecting the transglycosylation of a $\mathrm{GH} 1 \beta$-glucosidase. Appl Microbiol Biotechnol 101:1121-1131. https://doi.org/10.1007/ s00253-016-7

McCranie EK, Bachmann BO (2014) Bioactive oligosaccharide natural products. Nat Prod Rep 31:1026-1042. https://doi.org/10.1039/C3NP70128J

Moracci M, Trincone A, Rossi M (2001) Glycosynthases: new enzymes for oligosaccharide synthesis. J Mol Catal B-Enzym. 11:155-163. https:// doi.org/10.1016/S1381-1177(00)00084-9

Moremen KW, Haltiwanger RS (2019) Emerging structural insights into glycosyltransferase-mediated synthesis of glycans. Nat Chem. 15:853-864. https://doi.org/10.1038/s41589-019-0350-2
Noor E, Haraldsdóttir HS, Milo R, Fleming RMT (2013) Consistent estimation of Gibbs energy using component contributions. PLoS Comput Biol 9:e1003098. https://doi.org/10.1371/journal.pcbi.1003098

Perugino G, Trincone A, Rossi M, Moracci M (2004) Oligosaccharide synthesis by glycosynthases. Trends Biotechnol 22:31-37. https://doi.org/10. 1016/j.tibtech.2003.10.008

Qin Z, Li S, Huang X, Kong W, Yang X, Zhang S, Cao L, Liu Y (2019) Improving galactooligosaccharide synthesis efficiency of $\beta$-Galactosidase Bgal 1-3 by reshaping the active site with an intelligent hydrophobic amino acid scanning. J Agric Food Chem 67:11158-11166. https://doi.org/10. 1021/acs.jafc.9b04774

Ravet C, Thomas D, Legoy MD (1993) Gluco-oligosaccharide synthesis by free and immobilized $\beta$-glucosidase. Biotechnol Bioeng 42:303-308. https://doi.org/10.1002/bit.260420306

Rosengren A, Reddy SK, Sjöberg JS, Aurelius O, Logan DT, Kolenová K, Henrik Stålbrand H (2014) An Aspergillus nidulans $\beta$-mannanase with high transglycosylation capacity revealed through comparative studies within glycosidase family 5. Appl Microbiol Biotechnol 98:1009110104. https://doi.org/10.1007/s00253-014-5871-8

Rosengren A, Butler SJ, Arcos-Hernandez M, Bergquist KE, Jannasch P, Stålbrand $H$ (2019) Enzymatic synthesis and polymerisation of $\beta$-mannosyl acrylates produced from renewable hemicellulosic glycans. Green Chem 21:2104-2118. https://doi.org/10.1039/C8GC03947J

Salgado JCS, Meleiro LP, Carli S, Ward RJ (2018) Glucose tolerant and glucose stimulated $\beta$-glucosidases-a review. Bioresour Technol 267:704-713. https://doi.org/10.1016/j.biortech.2018.07.137

Sanz ML, Gibson GR, Rastall RA (2005) Influence of disaccharide structure on prebiotic selectivity in vitro. J Agric Food Chem 53:5192-5199. https:// doi.org/10.1021/jf050276w

Schägger H (2006) Tricine-SDS-PAGE. Nat Protoc 1:16. https://doi.org/10 1038/nprot.2006.4

Schmaltz RM, Hanson SR, Wong CH (2011) Enzymes in the synthesis of glycoconjugates. Chem Rev 111:4259-4307. https://doi.org/10.1021/ cr200113w

Seidle HF, Huber RE (2005) Transglucosidic reactions of the Aspergillus niger family $3 \beta$-glucosidase: qualitative and quantitative analyses and evidence that the transglucosidic rate is independent of $\mathrm{pH}$. Arch Biochem Biophys 436:254-264. https://doi.org/10.1016/j.abb.2005.02.017

Semenova MV, Okunev ON, Gusakov AV, Sinitsyn AP (2015) Disaccharide synthesis by enzymatic condensation of glucose: glycoside linkage patterns for different fungal species. Open Glycosci. 2:20-24. https:// doi.org/10.2174/1875398100902010020

Tan RS, Hinou H, Nishimura SI (2016) Novel $\beta$-galactosynthase- $\beta$ mannosynthase dual activity of $\beta$-galactosidase from Aspergillus oryzae uncovered using monomer sugar substrates. RSC Adv. 6:50833-50836. https://doi.org/10.1039/C6RA08060J

Wang F, Wu J, Chen S (2018) Preparation of gentiooligosaccharides using Trichoderma viride $\beta$-glucosidase. Food Chem 248:340-345. https://doi. org/10.1016/j.foodchem.2017.12.044

Wang L, Song L, He X, Teng F, Hu M, Tao Y (2019) Production of isofloridoside from galactose and glycerol using $\beta$-galactosidase from Alicyclobacillus hesperidum. Enzyme Microb Technol 134:109480. https://doi.org/10. 1016/j.enzmictec.2019.109480

Waterhouse A, Bertoni M, Bienert S, Studer G, Tauriello G, Gumienny R, Heer FT, de Beer TAP, Rempfer C, Bordoli L, Lepore R, Schwede T (2018) SWISS-MODEL: homology modelling of protein structures and complexes. Nucleic Acids Res 46:W296-W303. https://doi.org/10.1093/ nar/gky427

Wen L, Edmunds G, Gibbons C, Zhang J, Gadi MR, Zhu H, Fang J, Liu X, Kong Y, Wang PG (2018) Toward automated enzymatic synthesis of oligosaccharides. Chem Rev 118:8151-8187. https://doi.org/10.1021/acs.chemr ev.8b00066

Xia Y, Yang L, Xia L (2018) Preparation of a novel soluble inducer by cellobiaserelease microcapsules and its application in cellulase production. J Biotechnol 279:22-26. https://doi.org/10.1016/j.jbiotec.2018.05.002

Xin Y, Liu H, Cui F, Liu H, Xun L (2016) Recombinant Escherichia coli with sulfide: quinone oxidoreductase and persulfide dioxygenase rapidly oxidises sulfide to sulfite and thiosulfate via a new pathway. Environ Microbio 18:5123-5136. https://doi.org/10.1111/1462-2920.13511

Xu L, Liu X, Yin Z, Liu Q, Lu L, Xiao M (2016) Site-directed mutagenesis of a-I-rhamnosidase from Alternaria sp. L1 to enhance synthesis yield of 
reverse hydrolysis based on rational design. Appl Microbiol Biotechnol 100:10385-10394. https://doi.org/10.1007/s00253-016-7676-4

Yang J, Yan R, Roy A, Xu D, Poisson J, Zhang Y (2015) The I-TASSER suite: protein structure and function prediction. Nat Methods 12:7-8. https://doi.org/ 10.1038/nmeth.3213

\section{Publisher's Note}

Springer Nature remains neutral with regard to jurisdictional claims in published maps and institutional affiliations.
Submit your manuscript to a SpringerOpen ${ }^{\odot}$ journal and benefit from:

- Convenient online submission

- Rigorous peer review

- Open access: articles freely available online

- High visibility within the field

- Retaining the copyright to your article

Submit your next manuscript at $\boldsymbol{\nabla}$ springeropen.com 